\title{
EL PAPEL DE LA BLOGOSFERA EN LA CONSTRUCCIÓN SOCIAL DE LA MATERNIDAD: DE LA VIRGEN MARÍA A LAS \#MALASMADRES
}

Mariona Visa Barbosa ${ }^{1}$ Universitat de Lleida. España. marionavisa@filcat.udl.cat

Cira Crespo Cabillo. Universitat Autònoma de Barcelona. España. ciracrespo@gmail.com

\section{RESUMEN:}

Este artículo traza un recorrido histórico con el objetivo de analizar la representación de la figura de la madre desde la época pre moderna hasta la actualidad. De la imagen creada por las instituciones y los medios de comunicación (partiendo de la figura de la Virgen María y el llamado "Ángel del Hogar") hasta la madre actual definida en primera persona en los discursos de las redes sociales de Internet, veremos la evolución de la concepción social de la maternidad. En la blogosfera maternal ha prevalecido un discurso a favor de la maternidad intensiva (Hays,1998), aunque también han aparecido las autodenominadas \#malasmadres, con un relato en el que la maternidad es vivida de manera más realista. De todas maneras, estos testimonios se quedan en la epidermis del debate y no han construido hasta el momento un discurso maternal realmente subversivo, que desdibuje o conteste los tópicos tradicionalmente asociados a la maternidad.

PALABRAS CLAVE: maternidad- redes sociales- Internet- medios de comunicaciónVirgen María- representación- blogosfera

\section{BLOGS' ROLE IN THE SOCIAL CONSTRUCTION OF MOTHERHOOD: FROM VIEGIN MARY TO \#MALASMADRES}

\section{ABSTRACT:}

\footnotetext{
${ }^{1}$ Mariona Visa Barbosa: Doctora en Comunicación Social por la Universitat de Lleida y licenciada en Comunicación Audiovisual por la Universitat Pompeu Fabra de Barcelona. Es profesora investigadora en la Universitat de Lleida, en el Grado de Periodismo y Comunicación Audiovisual, y es miembro del Grupo de Investigación GECIEC (Grup d'Estudis de la Cultura i les Identitats a l'Europa Contemporània).

Correo: marionavisa@filcat.udl.cat
} 
This article provides a historical overview with the aim of analyzing the representation of the mother figure from the pre-modern period to the present. We will see the evolution of the social conception of motherhood from the image created by institutions and media (based on the Virgin Mary figure) to the current discourses made by mothers themselves in social networking sites. In the so-called maternal blogosphere has prevailed a speech in favor of intensive motherhood (Hays, 1998), but have also appeared the \#malasmadres with a more realistic view of motherhood. Anyway, these testimonies are left in the epidermis of the debate and have not already built a truly subversive maternal discourse that blurs or answers the topics traditionally associated with motherhood.

KEY WORDS: motherhood- social networking- Internet- media- Virgin Mary representation- blogs

\section{INTRODUCCIÓN}

Durante siglos la maternidad, como práctica social, ha sido construida y definida por instituciones como la religión, la educación o los medios de comunicación. Partiendo desde una visión patriarcal de la familia y la sociedad, estas instituciones han incidido en una imagen totalmente positiva, idealizada y sin sombras de lo que significa ser madre. Así, la experiencia subjetiva de la maternidad que viven las mujeres ha estado siempre influenciada por la representación que han hecho otros de esta etapa, de la que históricamente se han silenciado los aspectos negativos.

A partir del siglo XX, los medios de comunicación masiva, amplificadores y difusores de los mitos que conforman el imaginario colectivo, redundaron en el concepto de madre perfecta. Todo ello, entrando en contradicción con la realidad social, ya que la incorporación al trabajo de las mujeres las imposibilitaba de seguir siendo las máximas y únicas responsables del cuidado del hogar. Esta imagen disonante de la madre que se representaba desde los medios, empezó a generar, desde un contexto artístico a partir de la segunda mitad del s.XX, reacciones de madres que reclamaban su individualidad y su voz propia.

\section{OBJETIVOS}

En esta comunicación realizaremos un recorrido histórico que analiza la representación en la sociedad de la figura de la madre desde la época pre-moderna hasta la actualidad. La finalidad es observar cómo se ha generado una imagen idílica, marcada por la figura de la Virgen María y completada por la del "Ángel del Hogar" difundido desde los países protestantes-capitalistas.

\section{METODOLOGÍA}

Actualmente la posibilidad de expresión personal a grandes audiencias a través de las redes sociales ha favorecido y ampliado las narrativas en torno a la maternidad. Muchas madres anónimas plasman sus testimonios sobre la experiencia maternal en 
plataformas de socialización online, como la llamada "blogosfera maternal" o la página web El club de las \#malas madres que aquí estudiaremos.

Por lo que se refiere al análisis de la presencia de nuevos referentes en la blogosfera, este articulo parte de un estudio previo realizado por las mismas autoras titulado Las madres toman la palabra: Análisis del fenómeno de los blogs de madres (Visa; Crespo; 2012) en el que se realizó un análisis de contenido de los 10 blogs sobre maternidad escritos en castellano con más seguidores. En el presente artículo, con la finalidad de observar la pluralidad y evolución de los discursos que las madres anónimas realizan en Internet, estos datos se complementan con el análisis de 50 entradas del blog de la página web El club de las \#malasmadres, portal que aglutina experiencias de diversas mujeres y que cuenta en marzo de 2015 con más de 61.241 seguidores en Facebook y 15.400 en twitter.

A partir del análisis de diversos testimonios de madres en la red, veremos si estas plataformas han servido para llenar de nuevos matices la figura de la madre o si por el contrario sigue imperante el ideal de maternidad como experiencia siempre positiva y realizada con un amor maternal vinculado a la mujer de manera instintiva.

\section{RESULTADOS}

\subsection{La construcción de la maternidad: De la Virgen María al Ángel del Hogar.}

Diversas imágenes han contribuido a la actual concepción de la maternidad en Occidente. En este apartado vamos a destacar dos, que creemos ejes fundamentales sobre los que se ha construido nuestras narrativas al respecto; la Virgen María de la tradición cristiana y el Ángel del hogar construido por la sociedad capitalistaanglosajona. En pleno s.XX será esta visión edulcorada y falseada fuente de contestación por parte de la nueva mujer que se va construyendo y que reclamaba su individualidad y voz propia.

La mitología clásica (Alganza, 2003, p. 1-92), los cuentos, las historias de todos los pueblos están llenas da madres y madrastras ${ }^{2}$ que trazan el imaginario colectivo de las culturas donde estas se cuentan. En Occidente debemos lamentarnos por la poca diversidad de caracteres que nos construyen. Porque es básicamente la mitología de la Virgen María la que ha incidido en nuestro imaginario. Una madre sin aristas ni sombras. Los peligros de esta visión idealizada nos lo señalan desde el psicoanálisis, S. Birkhäuser-Oeri $(2011,9)$ :

La Virgen María aparece en la tradición solo como una figura luminosa. Esto tiene efectos perniciosos, sobre todo para las mujeres. Pues para ser una totalidad, la mujer necesita la imagen de la totalidad femenina, es decir, de un dios que no

\footnotetext{
${ }^{2}$ La figura de la madrastra está muy presente en la cultura popular europea y ha servido tradicionalmente como contrapunto a la buena madre. La madrastra es encarnación, en cierta manera, de todo lo malo que puede ser una cuidadora, afianzando la idea de que la biología ayuda en la creación de vínculos con los niños (S. Birkhäuser-Oeri, Madres y madrastras en los cuentos infantiles, Turner editorial, 2010, p. 29).
} 
encare solo la parte luminosa (...) Si, por el contrario, desconoce a la madre sombría de su misma, corre el peligro de identificarse con su aspecto luminoso. Vive entonces la parte destructiva, pero de manera inconsciente, es decir, reprimiéndola, lo que puede resultar muy peligroso para ella y para los demás.

A esa imagen que llegó desde la ortodoxia cristina (sobre todo en los países católicos), debemos añadirle, la figura de la ama de casa perfecta, que será encumbrada en la Inglaterra victoriana, con la Reina Victoria como estandarte ${ }^{3}$

La madre se definirá según los ideales capitalistas. Ella deberá educar a los ciudadanos en el orden económico. Su función es primordial. Es el eje vertebrador desde el que se erigirán los modelos, las morales y desde el que se reproducirá el sistema. Todo un entramado moral y educacional que debía sostener la estructura económica y social.

La construcción de este estereotipo femenino no se refiere únicamente por la maternidad. La mujer de esta nueva burguesía se debía a su hogar, debía responder y servir al productor de bienes principal, al señor de la casa. El cuidado a sus hijos era uno más de sus atributos. Una de sus principales características: que no fuera conflictiva ni tuviera deseos y personalidad propia.

Así la definía Virginia Wolf en el discurso que dio en 1931 y que llevaría por título "Professions for women":

Quizá no hayáis oído hablar de esta mujer, quizá no sepáis el significado de mis palabras cuando me refiero al Ángel de la Casa. La describiré con la mayor brevedad posible. Era intensamente comprensiva. Era intensamente encantadora. Carecía totalmente de egoísmo. Destacaba en las difíciles artes de la vida familiar. Se sacrificaba a diario. Si había pollo para comer, se quedaba con el muslo; si había una corriente de aire, se sentaba en medio de ella; en resumen, estaba constituida de tal manera que jamás tenía una opinión o un deseo propios, sino que prefería siempre adherirse a la opinión y al deseo de los demás. Huelga decir que, sobre todo, era pura. Se estimaba que su pureza constituía su principal belleza. Su mayor gracia eran sus rubores. En aquellos tiempos, los últimos de la reina Victoria, cada casa tenía su Ánge ${ }^{\dagger}$

En lo que se refiere a la maternidad o relación con sus hijos, tal y como se puede leer en la novela por entregas "Diario de una Dama de Provincias" -en este diario se cuentan los sinsabores de una madre de clase media alta en una zona rural inglesa

\footnotetext{
${ }^{3}$ Para profundizar, Sally Shuttleworth, "Demonic Mothers: Ideologies of Bourgeois Motherhood in the Mid-Victorian Era," en Rewriting the Victorians: Theory, History, and the Politics of Gender, ed. Linda M. Shires (London: Routledge, 1992): 31-51 y Abrams, Lynn. "Ideals of Womanhood in Victorian Britain." BBC History, 2001. Web. 28 March 2012.

${ }^{4}$ El texto se puede encontrar sin dificultad en la red, ya que los textos de V. Woolf están libres de copyright, aun así, este en concreto se publicó dentro del volumen Las Mujeres y la Literatura, ed. Lumen, 1981.
} 
de manera irónica-, se puede ver a lo largo del relato que para ser una mujer decente era necesario también vivir la relación con los hijos desde la distancia y la autoridad.

Vicky se ve estupenda montada en el poni, y me dirigen cumplidos sobre ella, que acepto con apatía y cierta incredulidad para demostrar que soy una madre moderna que no se rebaja a alardear como una tonta de sus hijos (Delafield, 2013, p.113)

Por otro lado, como se puede ver, se emplean palabras como Virgen María, Ángel, en definitiva, no es exagerado referirse a la creación de la mística de la maternidad. Así definía el amor maternal A. Halliday's en el artículo "Mother's" de 1865: "Es una pasión santa, en la que todos los otros son absorbidos y perdieron. Es una llama sagrada en el altar del corazón, que nunca se apaga" ${ }^{5}$

Encumbrando a las madres (a las mujeres) a una esfera religiosa, no real, no humana, lo que se consiguió, como se verá, fue frustración, pues estos son, simplemente, modelos irrealizables.

Por otro lado, el análisis de la construcción de la madre ideal no estaría completo si no nos refiriéramos al auge importantísimo de las teorías psicoanalíticas a principios del s.XX y la relevancia que a partir de entonces tomó la etapa de la infancia. Si bien esta mirada nueva hacia los más pequeños ha tenido innegables ventajas, ha supuesto también nuevas cargas a las ya habituales, pues la madre se sentirá a partir de entonces responsable principal (en ocasiones única) de la salud emocional de sus hijos. (Visa, Crespo, 2014, p.18)

"La maldición del psicoanálisis "todo se decide antes de los 3 años", me la sé de memoria"se lamenta Annie Ernaux en su relato "La mujer helada"(Davey, 2007, p.135).

Con estos ítems, llegamos a mediados del s.XX. Es entonces cuando se da el gran salto en la construcción de un imaginario. La llegada de los medios de comunicación de masa hará que los discursos morales y ejemplarizantes de las clases medias y altas, penetren también en las clases populares. La madre buena sin sombras, sin juicio ni deseos propios que debía atender a toda su familia, procurando por la salud física y emocional de todos sus miembros, excepto la suya propia, entrará en cada hogar, en cada estrato social. También las madres trabajadoras, también aquellas que no están en casa, también las que tienen unas condiciones de vida más paupérrimas se sentirán responsables y culpables de su situación y la de sus hijos.

De esta manera, con la incorporación mayoritaria de la mujer al trabajo asalariado, el modelo estará plenamente asumido e interiorizado. Este es también el momento en

\footnotetext{
${ }^{5}$ It is altogether above reason; it is a holy passion, in which all others are absorbed and lost. It is a sacred flame on the altar of the heart, which is never quenched" (Traducción propia). Andrew Hallaiday's, "Mother's", All the Year Round, 9 de agosto de 1965.
} 
que las mujeres que habían empezado a vivir su individualidad gracias al auge de los movimientos feministas. El modelo se tambalea y empieza a cuestionarse por algunas voces. Se vislumbra las sombras a la madre perfecta. Las aristas empiezan a relatarse en las narrativas de las mujeres creadoras. En muchos casos, aquellas que no son madres intentarán seguir el modelo de Virginia Wolf y harán lo posible por matar ese ángel, intentando no llevarse por delante también la infancia de sus hijos:

Me volví hacia el Ángel y le eché las manos en el cuello. Hice cuanto pude para matarlo. Mi excusa, en el caso de que me llevaran ante los tribunales de justicia, sería la legítima defensa. Si no lo hubiera matado, él me hubiera matado a mí. Hubiera arrancado el corazón de mis escritos (Davey, 2007, p.135)

\section{2. La representación de la maternidad en los medios de comunicación de masas del siglo XX}

En primer lugar, antes de entrar a valorar la figura de la madre en los medios de comunicación de masas, cabe subrayar que la figura de la madre ha tenido poco peso en los productos audiovisuales ya que sus contenidos han tendido a conformar un ideal de belleza femenino desligado de la maternidad y por tanto han sido pocas las madres que han tenido un papel como personajes protagonistas en la ficción cinematográfica o televisiva. (Huston, 2013). Cuando ésta ha sido representada, se ha hecho desde una visión patriarcal y deudora de los mitos maternales positivos anteriormente comentados.

En el cine clásico americano, que fue el hegemónico durante décadas tanto en los países anglosajones como europeos, los personajes maternos fueron caracterizados según estas dos facetas antagónicas: o la madre fálica todopoderosa (silenciosa, sacrificada y relegada al hogar) o la madre castradora que sobreprotege a sus hijos, que la adoran y la temen a la vez (numerosos ejemplos pueden encontrarse en las películas de A. Hitchcock). Sólo décadas más tarde, el cine de terror y de cienciaficción añade otra categoría más: la madre vista como una amenaza a causa de una maternidad vivida de manera anómala, forzosa o monstruosa (Merás, 2012), que puede verse en películas como Alien (Ridley Scott, 1979).

Por lo que respecta a las ficciones televisivas, desde la primera aparición de una mujer embarazada en la comedia norteamericana I love Lucy (1953) hasta las sitcoms de finales del siglo XX, la maternidad se presentó como una experiencia gratificante y natural en la mujer. A pesar de la masiva incorporación de las mujeres al trabajo, los personajes maternos en la pantalla tardaron en incorporar la angustia por la conciliación, y propagaron la imagen de una "súper-mujer" capaz de prosperar en el trabajo a la vez que cuidar a sus hijos sin complicaciones y sin tener sentimientos encontrados ante esta situación. (Pérez, 2014). No es hasta la década de los noventa y en particular a partir de la llamada "Quality Television" de principios del siglo XXI, que las madres protagonistas de las series empezarán a ser representadas de manera poliédrica (Tous, 2012) 
La imagen de una madre devota, complaciente y que sabe siempre cómo actuar es la que se hizo más visible en la televisión, también a causa de los estereotipos perpetuados todavía actualmente por los mensajes publicitarios. Estos mensajes han elaborado un discurso en el que la mujer aparece como la máxima responsable del cuidado del hogar y de los hijos, con eslóganes que elogian la maternidad e inciden, a menudo a través del humor y la exageración, en la incompetencia de los hombres a la hora de realizar estas mismas tareas domésticas. (Villegas, 2014).

Al definir esta imagen de "buena madre", lógicamente se define también su contrario, la "mala madre", que aparece en los medios en ocasiones a través de informaciones relativas a madres que tienen una conducta violenta hacia sus hijos 0 son negligentes en su cuidado. Un prototipo de madre que aparece siempre estigmatizado, visto como anti-natural y con el cual ninguna mujer querría identificarse.

Las revistas especializadas en puericultura y el cuidado del bebé, por su parte, también han alimentado el discurso hegemónico en el que la madre es la responsable principal y última de desarrollo del niño, y en ellas se añade a menudo la presión de estar bien informadas de los últimos avances relativos a la crianza, introducidos siempre por especialistas que desacreditan las opiniones que normalmente se reciben por parte del entorno familiar. (Medina et al, 2012). Su discurso, además, no se dirige a una pluralidad de madres con necesidades comunes que puedan ser enumeradas y solventadas de forma colectiva, sino que al dirigirse a cada lectora de forma individual no hay ninguna posibilidad de convertir el problema personal en social y por tanto, en político. (Gallego, 1990, p.54).

Desde las revistas del corazón, durante las últimas décadas del siglo XX, las llamadas "celebrety mums"(actrices o modelos famosas que son madres) han llenado las portadas posando como madres devotas y felices, que se sienten transformadas y plenas a raíz de su maternidad, que no ha supuesto ninguna renuncia en su carrera profesional ni ha dejado ningún rastro en su cuerpo. Esta concepción de la maternidad definida como "momism" (Douglas, Michaels; 2004), en referencia a la intensidad con que las madres se dedican a sus hijos, es muy contradictoria, ya que promueve un ideal imposible sugiriendo que la mujer debe trabajar fuera de casa con éxito y vivir a la vez la maternidad de manera intensa.

Como vemos, en los principales medios generalistas del siglo XX la madre se ha representado con un alto nivel de excelencia, sin ofrecer un discurso alternativo.

\subsection{La figura de la madre en el arte y la literatura en el siglo XX}

Durante el pasado siglo la figura maternal tampoco estuvo muy presente en las representaciones culturales (Freixas, 2012), aunque se encuentran algunas pocas excepciones de madres que, desde el contexto artístico, han ofrecido testimonios contrarios a la visión hegemónica de la "buena madre" presente en los medios. En el citado libro Maternidad y creación se recopilan testimonios de madres artistas como los de Doris Lessing, Tillie Olsen, Annie Ernaux, Toni Morrison o Margaret Adwood y, 
a través de extractos de sus autobiografías, memorias y novelas se abordan directamente una amplia categoría de sentimientos maternales, como la pérdida de control, el estado emocional alterado o el rechazo a encargarse de las tareas de limpieza y mantenimiento del hogar. Se empezaban a elevar así las primeras voces que cuestionaban la imagen de maternidad como el umbral a una experiencia feliz que convierte la mujer en una persona plena.

No sabía que era muy afortunada al existir en un momento histórico en que determinadas mujeres escritoras, la mayoría en el más riguroso aislamiento, al no ser conscientes de la existencia de otras mujeres, crispadas por la pena, el dolor, el miedo a la locura, la locura misma (...) estaban escribiendo por primera vez directamente $y$ en profundidad de su experiencia femenina" A. Ostriker. Una suposición atrevida: maternidad y poesía (Davey, 2007, p.165)

En el cine encontramos también algunas producciones que contestan la imagen predominante de la maternidad, aunque escasas y distribuidas al margen de la industria. La cineasta Alice Guy, mujer pionera en la realización cinematográfica, ya había filmado durante los primeros años del cinematógrafo un gran número de cortometrajes protagonizados por madres no estereotipadas que actuaban según sus propios deseos, retratados a partir del sentido del humor (como en Madame a des envies, 1906). A partir de la década de los sesenta, algunas piezas documentales creadas por mujeres filmaron el entorno cotidiano de manera subversiva. El rechazo al espacio doméstico, los rituales de la vida diaria y la presentación de un cuerpo de la mujer de manera realista son temas recurrentes en la obra de la directora belga Chantal Akerman y también en otras como Schmeerguntz (1965), de Gunvoe Nelson y Dorothy Wiley, en el que se muestra el embarazo de una de ellas; o Las Margaritas (1966), de Vêra Chytilová, en el que aparecen dos mujeres que actúan de manera libre y sin responder a los roles asignados.

También en el arte se encuentran algunas voces disidentes y que matizan el imaginario de la maternidad con experiencias individuales. Mujeres que se atreven a representar el cuerpo femenino durante el posparto y la crianza, reflejando los cambios físicos y emocionales que en él se producen, con sentimientos que aparte de la felicidad y plenitud incluyen también el cansancio y la desorientación. Un ejemplo lo encontramos en el proyecto Post-Partum Document, (1973-1979), realizado por la británica Mary Kelly. En él la artista explora artísticamente, bajo una perspectiva psicoanalítica, la relación con su hijo durante los primeros seis años de crianza, desde el nacimiento hasta que el niño se convierte en una persona autónoma. A través de numerosos documentos se explora la identidad de la mujer como madre y artista y la vez se representa la dificultad en asumir el papel que la sociedad patriarcal otorga como "natural" en la mujer.

Más recientemente, en 2013, la artista Ana Casas Broda presentó el proyecto fotográfico Kinderwunsch (un término alemán que combina las palabras niños y deseo) en el que se auto fotografió en distintos momentos cotidianos durante siete años, ilustrando su proceso de convertirse en madre, con la plasmación de momentos de juego y comunión con otros de agotamiento y rutina. 
Se empezaba así a contestar el ideal maternal imperante en los medios, aunque todavía desde contextos minoritarios. Cabría esperar a la expansión de Internet para que estas reflexiones pudieran ser hechas por más mujeres y llegar también a sectores mayoritarios de la sociedad.

\subsection{La blogosfera maternal: Un discurso plural sobre el significado de la maternidad. La rebelión contra la "súper-madre"}

En pleno siglo XXI, la posibilidad de expresión de los sentimientos generados por la maternidad a grandes audiencias es accesible también para las mujeres anónimas, que desde sus casas disponen de plataformas para documentar su vida cotidiana como madres. La expansión de Internet, que empezó a hacerse común en la década de los 90 del siglo XX, permite un rápido acceso a la información y también la creación de comunidades online (Weinberg 2003 ) gracias a la aparición de las redes sociales que han conseguido millones de usuarios en los primeros años del siglo XXI (Blogger, 1999; Myspace, 2003; Facebook, 2004; Twitter, 2006). Estas páginas permiten que cada usuario pueda tener un espacio propio en la red para contar sus experiencias y compartirlas con otros. Nunca antes se había podido amplificar tanto la experiencia personal.

El número de blogs en los que las madres expresan sus experiencias personales no para de crecer desde su emergencia en el año $2010^{6}$ y en numerosos países occidentales son un referente para muchas otras madres. Estas voces que narran los sentimientos que despierta la maternidad favorecen que el discurso hasta ahora único y mediatizado por las instituciones, sea más plural y difundido por las propias madres. Los estereotipos unificadores ya no son válidos, sino que surgen las individualidades.

En los textos de estos blogs se reivindica el cuerpo de la madre; se cuestiona el mito de la "súper-madre"omnipresente hasta la fecha en los medios de comunicación y se manifiesta la voluntad de describir de forma más realista la maternidad. De hecho, el choque que supone vivir la experiencia frente a lo que anteriormente se había imaginado es uno de los motivos argumentados a menudo por las autoras para abrir un blog.

La difícil conciliación entre la vida laboral, la personal y la familiar es uno de los temas más debatidos en estas páginas personales. En 2011, a raíz de la queja de una madre se creó la plataforma Conciliación Real-ya, que movilizó en pocos días a más de 1000 personas. Actualmente sigue activa promoviendo un cambio de mentalidad para poder conseguir una conciliación real, intentando demostrar que con la mejoría de las condiciones laborales, el rendimiento es mucho mayor en todos los ámbitos.

\footnotetext{
${ }^{6}$ La página Madresfera, que aglutina blogs sobre maternidad y paternidad escritos en castellano cuenta en enero de 2015 con más de 1500 blogs.
} 
Estas palabras del blog Mama también sabe, ejemplifican este discurso alejado del ideal de madre perfecta:

El día tiene sólo 24 horas, yo tengo sólo dos manos y una sola cabeza, y por más que quiera, no llego a todo, no puedo, no debo, no quiero... No veo porqué se nos pide tanto, porqué hemos dejado que se nos siga exigiendo ser todo y más. Hemos pasado culturalmente de ser ninguneadas a ser hiperexplotadas, para poder ser dignificadas... pero estamos locas? A quién queremos impresionar? Yo por mi parte lo declaro alto y fuerte NO SOY SUPERMUJER y no pretendo serlo, y no quiero serlo. Me declaro libre de siquiera intentarlo. Conozco mis capacidades, pero también mis límites... y yo no puedo sentirme culpable por no poder hacer todo al $100 \%^{7}$

Junto a este discurso, también se ha hecho presente, en la gran mayoría de los blogs de maternidad tanto a nivel nacional como en el ámbito anglosajón una inclinación por la llamada "crianza natural", ya que las autoras narran su experiencia de la maternidad vivida de manera consciente con el propio cuerpo y el de los hijos; y se opta por vivir de la forma más natural posible (con las mínimas mediaciones médicas y técnicas) los procesos como el parto, la lactancia o el acompañamiento en el sueño de los niños.

Esta crianza natural, en la que la madre es la principal proveedora de las necesidades infantiles comparte algunos preceptos de los que Sharon Hays (1995) definió como maternidad intensiva. Ésta se define a través de tres principios fundamentales: inversión de una enorme cantidad de tiempo, energía, dinero y desgaste emocional en la crianza de los hijos; desprecio inicial de la aportación paterna a dicha crianza; y consideración de los niños como seres sagrados, inocentes, puros por naturaleza, que constituyen el polo opuesto de una sociedad mercantilista. Actualmente la madre ya no es en la mayoría de casos la principal cuidadora del niño, pero sí que sigue vigente la voluntad de destinar a éste grandes cantidades de tiempo, energía y recursos materiales. Existe una preocupación generalizada para reconocer y responder a todas las necesidades y deseos del niño, así como por estar al corriente de las opiniones de los expertos y de las nuevas tendencias educativas.

Igualmente, se ha definido como "nueva domesticidad" (Matchar, 2013) la revalorización de unas conductas más naturales en torno a la alimentación, el vestuario, la educación y en aplicar el "hazlo tú mismo" a la mayoría de esferas domésticas, corriente de la que también se encuentran ejemplos en la blogosfera. De todas maneras, creemos que este llamado "retorno a lo natural" hay que analizarlo en el contexto de crisis económica y moral, donde se cuestionan abiertamente muchos de los preceptos neoliberales. Muchas de las actitudes alrededor de la crianza, que intentan fomentar un apego más sólido de los niños (lactancias prolongadas, porteo, colecho) creemos que se deberían analizar como una especie de "solución de urgencia" enfrente una sociedad neoliberal que vive de espalda a los

\footnotetext{
${ }^{7}$ No soy superwoman". Blog Mamá también sabe. 04/03/2014
} 
cuidados y la crianza.

Por otra parte, es evidente que las dificultades por entrar en ciertos modelos y estándares, sigue vigente. Observamos por tanto que la pluralidad de voces en la blogosfera materna no tiene una única línea sino que aglutina tanto a madres trabajadoras que abogan por una verdadera conciliación como a madres que por voluntad propia o ante la imposibilidad de conciliar han decidido apearse del sistema y dedicarse en exclusiva a la crianza de sus hijos.

Por lo que respecta a otras redes sociales en las que las madres difunden su experiencia a través de imágenes, al contrario de la blogosfera dónde domina la palabra, encontramos otros relatos de la maternidad, más en línea a los preceptos que definieron a las buenas madres del siglo XX. En plataformas como Pinterest, Instagram o Facebook la imagen que se difunde de la maternidad tiende a ser más idílica, aunque cada vez se encuentran más excepciones. Al estar fragmentadas y no ir acompañadas de texto, las imágenes se observan a menudo fuera de contexto, sin más información que la misma fotografía, transmitiendo una idea de la maternidad y del posparto inmediato que tiene poco que ver con la realidad. Además, no debemos olvidar que en Instagram se pueden añadir filtros a las imagines para mejorarlas y dotarlas de una atmósfera más cinematográfica e idílica. No es de extrañar que algunos estudios ${ }^{8}$ demuestren que Facebook propicia estados depresivos y sentimientos de soledad a algunos de los usuarios que contemplan las fotografías, que tenderán a pensar que en casa de los demás se vive siempre una maternidad idílica.

Como reacción a esta idealización y como respuesta a los blogs dedicados a detallar la experiencia de maternidad vivida de forma perfecta y sin contradicciones, en diciembre de 2013 nació la página El club de las \#malasmadres, que aglutina textos de mujeres relatando con ironía momentos no idílicos de su maternidad. Con una estética vintage y festiva, la página invita a vivir esta etapa de manera desacomplejada. En el blog de su creadora y autora principal se encuentran textos en los que se comenta sin prejuicios que "la maternidad cansa" y se aboga por la necesidad de las madres de "buscarse un ratito para sí solas". La filosofía de este movimiento sigue los pasos de los blogs anglosajones Mother Uncensored o Her Bad Mother, en los que se pone de manifiesto que aparte de madres, somos mujeres y tenemos aficiones y necesidades más allá de criar a nuestros hijos.

El término \#malasmadres con el que se autodenominan resulta simbólico ya que sirve para construir un imaginario contrario al de la "buena madre" lejos de la maternidad negligente con el que se asociaba hasta ahora la palabra "mala madre". Tener voluntad de maquillarse, hablar de sexo, querer horas a solas o ir a un concierto con los amigos dejando al hijo a buen recaudo, lógicamente, no es ser una mala madre. ("el día de la boda, el día en el que el buenpadre y una servidora

\footnotetext{
${ }^{8}$ Hui-Tzu Grace Chou and Nicholas Edge. Cyberpsychology, Behavior, and Social Networking. February 2012, 15(2): 117-121. doi:10.1089/cyber.2011.0324. "They Are Happier and Having Better Lives than I Am":
} 
dejaron al buenhijo con los buenosabuelos, los buenostíos y la buenasobrina y dijeron "chau, chau, hasta mañana".), pero sirve para contestar la maternidad intensiva y reírse de la "súper-madre", que ya no es vista como el ideal a alcanzar. La madre imperfecta se reivindica como algo natural y que no genera sentimientos de culpabilidad. ("El precioso calendario de adviento que nos enseñó a hacer Paula es otro cantar, hemos intentado hacerlo y nos ha quedado un poco torcido diría yo').

De todas maneras, como veremos a continuación, estos testimonios se quedan en la epidermis del debate y no han construido hasta el momento un discurso maternal realmente subversivo, que desdibuje o conteste los tópicos tradicionalmente asociados a la maternidad.

\subsection{Las sombras de la maternidad en la blogosfera}

Hemos visto como el discurso que propone la página El club de las \#malasmadres y otos blogs similares de la blogosfera maternal incluye la renuncia al ideal de madre entregada al cuidado y al hogar de los hijos. Pero, a pesar de la posibilidad que ofrecen las redes sociales de expresar testimonios plurales, incluso de manera anónima, todavía cuesta encontrar textos que hablen de las sombras de la maternidad y de la parte negativa que ha supuesto para cada mujer el hecho de convertirse en madre. Son muy pocos los textos en los que algunas madres expresen no sentirse siempre felices y orgullosas de sus hijos, o que expresen con sinceridad las renuncias que esta experiencia les ha supuesto. Tampoco son habituales los relatos de mujeres que admitan estar sufriendo una depresión posparto, a pesar de estar ésta reconocida socialmente.

Como apunta Beatriz Gimeno, "No puede ser que de una experiencia humana con esa capacidad tan poderosa para cambiar la vida de cualquier mujer no existan

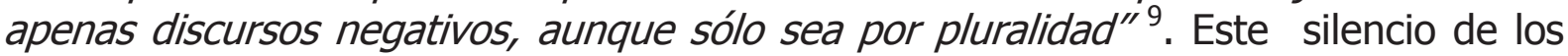
aspectos negativos de la maternidad puede ser debida en parte a lo que NoelleNeumann (1977) definió como la espiral del silencio, según la cual quiénes expresan sus pensamientos públicamente tienden a ser aquellos que tienen un modo de pensar más afín a las ideas hegemónicas. Las personas son más proclives a apoyar públicamente una opinión si esta aparece como dominante en los medios de comunicación. Por lo tanto, aquellos que tienen opiniones contrarias tienden a silenciarlas para evitar el aislamiento social. En un tema como la maternidad, del que históricamente sólo se ha publicitado la parte positiva, esta espiral es especialmente importante ya que hasta el momento contestar el tópico de la "buena madre" implicaba dejar de serlo y entrar en el espinoso terreno de las "malas madres", vinculado todavía a características de irresponsabilidad y negligencia.

Igualmente, la voluntad de escribir un blog público y compartir la experiencia es más fácil cuando esta experiencia es positiva. Elaborar una narrativa propia en los momentos traumáticos o de depresión requiere un mayor esfuerzo y voluntad, ya

\footnotetext{
${ }^{9} \mathrm{http}: / /$ beatrizgimeno.es/2014/02/13/construyendo-un-discurso-antimaternal/ (13-02-2014)
} 
que la persona está instalada todavía en la situación y no puede distanciarse para construir un relato inteligible. (Frank, 1995)

Poco a poco, probablemente favorecido por el anonimato que proporciona Internet, algunas madres sí se atreven a contar la otra cara de la maternidad. Sirvan como ejemplo estas palabras del post "La maternidad en el armario" del blog Mamá( contra corriente), que tiene más de 4500 seguidores en Facebook. y es uno de los más populares en la blogosfera maternal:

Pienso que es fácil explicar las cosas bonitas, hablar del amor que sientes, de cómo te ha cambiado la vida (para bien), de subir fotos de casas de inspiración nórdica en las que hasta los juguetes van a juego con la decoración o de atardeceres espectaculares o de manualidades chulísimas que tu sola has inventado. Es la clase de cosas que apetece compartir. Pero es complicado decir que lo estás pasando mal, no sólo ya por el hecho en sí de reconocer tu propia debilidad sino porque parece que ser feliz es obligatorio cuando eres madre (sobre todo si eres madre reciente) y porque, para qué negarlo, tienes miedo de que entiendan lo que no estás diciendo. Tienes miedo de que piensen mal de ti, de que piensen mal de tus hijos. Tienes miedo de todo y por eso callas. Pues bien, aquí estoy hoy destapando el tapón para poder seguir adelante: Los últimos dos años y medio están siendo muy duros. (...).La vida con un bebé de alta demanda de dos años y cinco meses es devastadora

Este post tuvo 141 comentarios, en muchos de los cuáles diversas madres reconocían sentirse identificadas con la autora. Fuera del discurso positivo o que reivindica con humor un nuevo estereotipo de madre también hay sitio, aunque todavía menor, para estas declaraciones. Y esta es una de las grandezas de la red, que permite que sean distintas las voces que conforman la definición de lo que significa ser madre.

Finalmente cabe señalar que tampoco son muy presentes las mujeres que confiesan abiertamente que no desean ser madres, aunque es un colectivo que empieza a visualizarse. En los últimos años el movimiento childfree (que agrupa a parejas sin hijos por elección) se ha hecho presente en los medios de comunicación, pero es simbolizado genéricamente por parejas heterosexuales que deciden libremente no ser padres, y todavía son pocas las particularizaciones en casos concretos. El movimiento No Mo.(Not Mothers):, surgido de asociación británica Gateway Women agrupa a mujeres que deciden no ser madres, reclamando "el respeto de una sociedad instalada en la absurda creencia de que una mujer debe dar a la luz al menos una vez en su vidd". Pero ciertamente hay poca presencia de estos testimonios en las redes sociales, aunque esperamos que con el tiempo esta situación cambie, y se empiecen a particularizar y ejemplificar más situaciones y circunstancias que llevan a cada mujer a no ser madre.

\section{DISCUSIÓN}


La imagen en positivo que se nos retrata en los medios de comunicación ha encorsetado gravemente la experiencia maternal. La madre perfecta, la madre ideal, está envuelta de características, no solo positivas, sino que sagradas. Por suerte, desde mediados del siglo XX se amplificaron las voces de madres que en primera persona cuestionaban las bondades de esa maternidad. Las narrativas se han multiplicado exponencialmente con la llegada de las redes sociales. Eso no significa necesariamente, diversidad.

A pesar de la aparición de voces como las de las \#malasmadres, consideramos que ciertamente son aún críticas muy amables, que no dan respuesta ni cuestionan las bases y los ejes de la maternidad construida desde el poder. Cabe señalar otros discursos más transgresores y de más profundidad, que han desatado grandes polémicas en las redes como el de la activista feminista Beatriz Gimeno y su autodenominado "discurso antimaternal".

Aun así, pensamos que no salimos del discurso binario. Como decía A. Ostriker, "que las mujeres deberían hacer bebés en lugar de hacer libros es la opinión de la civilización occidental. Que las mujeres deberían hacer libros en lugar de bebés es una variación sobre el mismo tema"(Davey, 2007, p.163).

Sería interesante, y tal vez más subversivo, ir más allá de denominaciones como "malas y buenas madres" o "anti maternal y pro maternal", porque enfrentan y no aportan propuestas inclusivas. Creemos más interesante responder a lo siguiente: ¿puedes criar hijos e hijas felices sin necesidad de seguir los modelos establecidos? ¿puedo ser una buena madre y a la vez cualquier mujer, aquella que se me ocurra?

Proponemos ser conscientes de nuestras incapacidades, de nuestras imperfecciones, asumirlas y dar buenos ejemplos, enseñar modelos de ser madre diferentes, construir discursos alternativos (y vidas alternativas) donde todas las partes implicadas en la crianza sientan cercana la posibilidad de ser felices. Desatarnos los corsés que nos constriñen y no nos dejan disfrutar plenamente de la experiencia maternal.

\section{BIBLIOGRAFÍA}

\section{LIBROS, CAPÍTULOS DE LIBRO O ENTRADA DE UN LIBRO DE CONSULTA, INFORMES TÉCNICOS, TESIS}

Roldán, M. A. (2003) Madres y madrastras en la tragedia y el mito griego. Lengua literatura y mujer

Birkhäuser, S. (2011). La llave de oro. Madres y madrastres en los cuentos infnatiles. Turner

Delafield, E.M. (2013). Diario de una dama de provincias, Libros del Asteroide.

Douglas, S. J.; Meredith M.. (2005) The mommy myth: The idealization of 
motherhood and how it has undermined all women. Simon and Schuster

Frank, A. W. (2013). The wounded storyteller: Body, illness, and ethics. University of Chicago Press.

Freixas, L. (2012). Maternidad y cultura. Claves de razón práctica 22. 8-19.

Gallego, J. (1990) Mujeres de papel. De iHola! a Vogue: la prensa femenina en la actualidad. . Barcelona, Icaria.

Hays, S. (1998) Las contradicciones culturales de la maternidad. Paidós Ibérica.

Huston, N. (2013). Reflejos en el ojo de un hombre. Galaxia Gutenberg.

Matchar, E. (2013) Homeward Bound: Why Women Are Embracing the New Domesticity.

Noelle-Neumann, E. (1995) La espiral de silencio. Opinión pública. Nuestra piel social. Paidós Ibéric

Richmond, K. (2004). Las mujeres en el fascismo español. Sección femenina de la falange 1934-1959. Alianza editorial

\section{PUBLICACIONES PERIÓDICAS, REVISTAS, WEBES Y SIMILARES:}

Cuesta, Li. (2008) El concepto de" maternidad": últimas tendencias dentro del feminismo." Clepsydra: revista de estudios de género y teoría feminista 7 169-184 Davey, M. (2007). Maternidad y creación. Lecturas esenciales. Alba editorial.

Chou, H. T:; Edge, N. (2012). They Are Happier and Having Better Lives than I Am": The Impact of Using Facebook on Perceptions of Others' Lives en Cyberpsychology, Behavior, and Social Networking. February , 15(2): 117-121. Doi:10.1089/cyber.2011.0324. "

Medina,, P.; Figueras, M.; Gómez-Puertas; L. (2014) El ideal de madre en el siglo XXI. La representación de la maternidad en las revistas de familia. Estudios sobre el Mensaje Periodístico 20.1 487-504.

Merás, L. (2012). Maternitats anòmales. Reproducció a la ciència ficció cinematogràfica dels anys noranta. Anàlisi: quaderns de comunicació i cultura 46: 35-47.

Palacio Lis, I. (2003). Madres ingnorantes, mujeres culpables. Universidad de Valencia

Pérez, E. H. (2014). Parodiando la frustración de la superwoman: Liz Lemon en el entorno laboral de Rockefeller Plaza: series de televisión; parodia; superwoman; $\square$ nàlisis del discurso. Revista de la SEECI, (34), 50-64. 
Schneider, S; Haim Weinberg, eds. (2003) The large group re-visited: the herd, primal horde, crowds and masses. Vol. 25. Jessica Kingsley Publishers

Shuttleworth, S. (1992). "Demonic Mothers: Ideologies of Bourgeois Motherhood in the Mid-Victorian Era," en Rewriting the Victorians: Theory, History, and the Politics of Gender, ed. Linda M. Shires . London

Villegas, J. C. S. (2014). El micromachismo en la publicidad Nuevas estrategias para viejos estereotipos:"mi marido me ayuda" y "el elogio de la maternidad". Pensar la Publicidad. Revista Internacional de Investigaciones Publicitarias, 72), 239-251.

Tous, A. (2012) La representación de los nuevos modelos de familia en las series televisivas estadounidenses. En De Anatomía de Grey a The wire. Los libros de la Catarata.

Visa, M.; Crespo, C. (2014) Madres en red. Del lavadero a la blogosfera. Clave Intelectual.

Pioneres del cinema: al marge de la industria. Soy Cámara. Programa del CCCB. Ingrid Guardiola; Marta Sureda.

\section{Autoras:}

\section{Mariona Visa Barbosa}

(Lleida, 1979) es doctora en Comunicación Social por la Universitat de Lleida y licenciada en Comunicación Audiovisual por la Universitat Pompeu Fabra de Barcelona. Es autora del libro "L'àlbum fotogràfic familiar. Un relat socialitzat de la pròpia vida." (Publicacions UDL, 2013) y co-autora de "Madres en red. Del lavadero a la blogosfera (Clave Intelectual, 2014).. Es profesora investigadora en la Universitat de Lleida, en el Grado de Periodismo y Comunicación Audiovisual, y es miembro del Grupo de Investigación GECIEC (Grup d'Estudis de la Cultura i les Identitats a l'Europa Contemporània).

orcid.org/0000-0002-9261-264X\#sthash.XiyZJUdQ.dpuf

\section{Cira Crespo Cabillo}

(Barcelona, 1980) Es doctora en Historia por la Universidad Autónoma de Barcelona y licenciada en historia por la misma Universidad, donde se formó en historia clásica y arqueología. En los últimos años ha dirigido sus investigaciones hacia la historia de la maternidad y su divulgación en redes sociales. Actualmente reside en el País Vasco donde colabora en algunos medios comunicación. Es autora del libro "Maternalias. De la historia de la maternidad" (ObStare, 2013) y co-autora de "Madres en red. Del lavadero a la blogosfera (Clave Intelectual, 2014). También es autora del blog Maternalias.blogspot.com, así como colaboradora en diversas plataformas on-line. 